Research Article

\title{
Prevalence of dental caries in male children from 3 to 14 years of age of Bundelkhand region, India
}

\author{
Arvind Jain ${ }^{1}$, Vandana Jain ${ }^{2}$, Sheenu Malik Suri², R. K. Jain ${ }^{3}$

\begin{abstract}
${ }^{1}$ Department of Conservative Dentistry \& Endodontics, Government College of Dentistry, Indore, MP, India
${ }^{2}$ Department of Department of Anatomy, MGM Medical College, Indore, MP, India

${ }^{3}$ Consultant paediatrician, Kilkari Child Care, Tikamgarh MP, India
\end{abstract}

Received: 12 March 2016

Accepted: 17 March 2016

\section{*Correspondence:}

Dr. Arvind Jain,

E-mail: drarvindendo@gmail.com

Copyright: ( ) the author(s), publisher and licensee Medip Academy. This is an open-access article distributed under the terms of the Creative Commons Attribution Non-Commercial License, which permits unrestricted non-commercial use, distribution, and reproduction in any medium, provided the original work is properly cited.

\begin{abstract}
Background: Dental caries is a public health problem in developing countries like India. The problem is dreadful among children particularly of low socio-economic status in rural area. The present study was planned to assess the prevalence of dental caries among children of rural Bundelkhand region.

Methods: The present study was conducted in the male children attending the paediatric OPD in Tikamgarh district of Madhya Pradesh. The age group considered for study was from 3 to 14 years of age.

Results: The overall prevalence of the dental caries in male children was found to be $82.62 \%$ with mean DMFT/dmft to be 3.58 and the prevalence is higher in middle childhood group of 7-10 years $(87.09 \%)$ as compared to pre-school group including 3-6 years $(81.07 \%)$ and late childhood group of $11-14$ years $(75.72 \%)$.

Conclusions: The study population showed a very high prevalence of $82.62 \%$ among male children of Bundelkhand region. It indicates the need for educating the population about the causative factors for dental caries and immediate intervention in the form of dental health education.
\end{abstract}

Keywords: Dental caries, Bundelkhand region, Male children, Prevalence

\section{INTRODUCTION}

Oral health is recognized as equally important parameter in relation to general public health. Oral diseases are a major public health concern owing to their higher prevalence and their effects on the individual's quality of life. ${ }^{1}$ According to the World Health Organization (WHO), promotion of oral health is a cost-effective strategy to reduce the burden of oral disease and maintain oral health and quality of life. ${ }^{2}$ Dental caries, with a prevalence as high as $60-80 \%$ in children, is a major public health problem in India. ${ }^{3}$ Dental caries continues to be the most common infectious disease of childhood. Its prevalence is high in the developing countries. It was observed that in 1940, the prevalence of dental caries in India was $55.5 \%$, during 1960 it was reported to be $68 \%{ }^{2}$ The prevalence of dental caries is approximately $60-65 \%$ in India. ${ }^{4}$ According to the Centers for Disease Control and Prevention (CDC), more than 19 percent of children have untreated cavities and approximately 41 percent of children have decay in their "baby teeth". 5 Voluminous literature exists on the status of the dental caries in the Indian population. In the year $1997,22.7 \%$ of Indian population was estimated to be 5-14 yrs. This being such a high proportion of the population, the prevalence of dental disease among this age group needs to be assessed. ${ }^{6}$

The unique characteristic of dental diseases including dental caries is that they are universally prevalent and do not undergo remission or termination if untreated and require technically demanding expertise and time consuming professional treatment. Dental caries show striking geographic variations, socio-economic patterns 
and severity of distribution all over the world. ${ }^{7}$ Dental hygiene is poor in India with improper brushing of teeth, no washing of mouth after intake of sweets, wide-spread addiction, hyperacidity, increased consumption of refined sugar and sweetened foods. ${ }^{8}$ To overcome untreated dental cavities, foremost necessity is to determine the extent and severity of dental cavitation in different regions of the country depending upon which further preventive strategy can be planned and executed. The objective of present study was to determine the prevalence of dental caries in the rural Bundelkhand region whose data is not available. The data would hence help in providing a standard baseline to plan interventional programmes for prevention of dental caries in children.

\section{METHODS}

The study was carried out in 656 male children ranging in the age group of 3 to 14 completed years who randomly visited the Paediatric OPD in Tikamgarh district of Madhya Pradesh in a period of nearly two years from March 2014-December 2015. Only those male children were included in respective groups of our study who completed age range of 3 years to 14 years confirmed from their birth certificate. Also only those male children were selected who belong to Bundelkhand region which is confirmed by their school certificates, birth certificates showing place of birth and identity proofs indicating their residence belonging to districts like Tikamgarh, Banda, Lalitpur, Sagar, Damoh etc. Those children who were belonging to other regions were excluded from study including children whose residence cannot be confirmed from records. The sample was examined with the prior permission of Medical officer of registered pediatrics OPD. The subjects were examined in an upright chair with adequate light. The children were examined by a single examiner (specialist dental surgeon) to avoid inter examiner variation. A recording clerk (Trained Dental Surgeon) was involved to enter the codes on the survey form. The present and past health status of each tooth was recorded in terms of the presence or absence of disease or a dental restoration. Only definite cavitation of the tooth surface was recorded as dental caries to reduce examiner confusion regarding diagnosis and exclusion of intact demineralized (white spot) lesions. Data collection extended over a period of two years. The records were maintained by a well-trained person who assisted throughout the study. Using World Health Organization (WHO) diagnostic criteria, the numbers of decayed, missing and filled teeth (dmft/DMFT) were recorded. In case of doubtful tooth, it was considered to be without caries i.e. $(\mathrm{D}=0)$. Clinical examinations included dental caries examination using WHO standard criteria as mentioned in WHO Oral Health Proforma, 2013. ${ }^{9}$

Children belonging to 3-6 years were classified under group-I, 7-10 years under group-II and 11-14 years under group-III.
For analysis students were categorized according to their caries experience,

1. Those without caries experience $(\mathrm{dmft} / \mathrm{DMFT}=0$; absence of decayed, missing tooth/teeth due to caries, or filled tooth/teeth.

2. Those with caries experience ( $\mathrm{dmft} / \mathrm{DMFT}>1)$; presence of one or more decayed, missing tooth/teeth due to caries, or filled tooth/teeth.

The statistical analysis was performed using the SPSS (10.0) software package.

\section{RESULTS}

A total of 656 male children of age group 3-14 years were examined during the study. Out of the study population $243(37.04 \%)$ were from group-I, 217 (33.08\%) from group-II and $206(31.4 \%)$ from group-III (Table 1).

Prevalence of caries was $81.07 \%$ in group-I i.e. 197 caries patients were found. In group-II caries prevalence was $87.09 \%$ i.e. 189 cases of dental caries were detected. Finally in group-III, caries prevalence was $75.72 \%$ as 156 cases of caries were found (Figure 1).

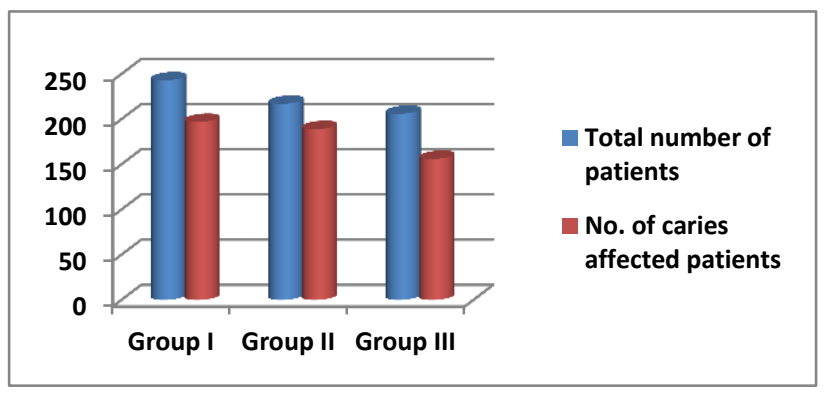

Figure 1: Representing no. of caries affected patients in study sample of various groups.

Caries prevalence of groups in percentage as per distribution of sample is shown in Figure 2.

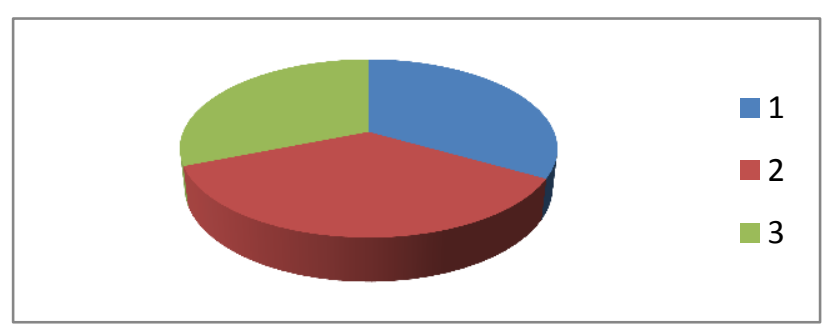

Figure 2: Caries prevalence in \% of various groups.

Thus in 656 study sample of male children $542(82.62 \%)$ of caries cases were detected with mean DMFT/dmft of 3.58 and 114 patients were caries free i.e $17.38 \%$ (Table $1)$. 
Table 1: Distribution of groups and its prevalence with mean DMFT/dmft.

\begin{tabular}{|llllll|}
\hline & & Caries absent & Caries present & Prevalence in \% & Mean DMFT/dmft \\
\hline Total & 656 & 114 & 542 & $82.62 \%$ & 3.58 \\
\hline Group-I & 243 & 46 & 197 & $81.07 \%$ & 3.42 \\
\hline Group-II & 217 & 28 & 189 & $87.09 \%$ & 3.86 \\
\hline Group-III & 206 & 50 & 156 & $75.72 \%$ & 2.28 \\
\hline
\end{tabular}

\section{DISCUSSION}

For individual social, economic and personal development, oral hygiene is significant which is a benchmark for a healthy mouth and prevents maximum dental problems. ${ }^{10}$ Our study lays down the figures indicating the gravity of dental caries in specific age group in a defined geographical region using WHO criterion. A total of 656 male children of age group 3-14 years were examined during the study and a very high prevalence of dental caries of $82.62 \%$ with mean $\mathrm{DMFT} / \mathrm{dmft}$ of 3.58 were found which indicates enormous dental problem indicating the very poor level of awareness of dental hygiene among the general population of Tikamgarh district. Similar study conducted by Poonam Shingare among 3 to 14 year old School Children in Uran Raigad District Maharashtra, showed the dental caries prevalence to be $80.92 \%$ with the mean DMFT/dmft to be $3.65 .{ }^{11}$ Ramachandran karunakaran et al conducted a similar study in 460 male school going children of Namakkal district of Tamilnadu and found the prevalence of dental caries to be $69.57 \%$ with the mean dmft score of $2.89 .{ }^{12}$ Datta P conducted similar study in school children of Sunderban district and found $68.8 \%$ male children of $13 \& 14$ years affected with dental caries. ${ }^{13}$ Hence dental caries show marked geographical variation along with variation in age. Desouza et al found that there was no significant difference in the caries status of children of 6-11 years whether assessed by CAST instrument or by WHO criterion. $^{14}$

High level of dental caries may be due to decrease literacy rate particularly maternal literacy, improper brushing technique including the usage/non-usage of tooth paste, nutritional status of children, frequent consumption of sweets and not rinsing their mouth after consuming eatables. ${ }^{15}$ Present study is undertaken in specific gender and in limited age group which limits the study to certain extent. Whether the high level of prevalence is also present in other age groups and in female population is unknown and needs to be investigated. Another significant assumption would be that the general population of Bundelkhand region does not give much importance to the health of girl child, that's why the study group was chosen to be males as their pediatric clinic visits were frequent. This assumption needs to be evaluated further. Urgent counseling of the general masses on a war footing is needed to prevent dental diseases. Also facilities at affordable cost need to be provided for early intervention. Awareness to the public may be increased by using audio-visual modes such as radio, televisions, magazines, newspapers, hand-outs, road shows and public notices. Parents and teachers including children must be encouraged to devote sufficient time for dental health education programs and diet counseling.

\section{ACKNOWLEDGEMENTS}

This study was conducted independently and not sponsored by any outside body. The author would like to thank all participants for their valuable help and cooperation. Dr. Pratesh (trained dental surgeon) for their participation.

\section{Funding: No funding sources Conflict of interest: None declared \\ Ethical approval: Taken prior permission from in charge of registered paediatric $O P D$}

\section{REFERENCES}

1. Butt AM, Ahmed B, Parveen N, Yazdanie N. Oral health related quality of life in complete dentures. Pak Oral Dent J. 2009;12:29-2.

2. WHO health. Action plan for promotion and integrated disease prevention. New York: World Health Organization; 2006.

3. Damle SG. Pediatric Dentistry. New Delhi: Arya Publishing House; 2002. Epidemiology of dental caries in India.

4. Khan AA, Jain SK, Shrivastav A. Prevalence of dental caries among the population of Gwalior (India) in relation of different associated factors. European J Dent. 2008;2(2):81-5.

5. Samadi D. Dental hygiene important for whole body, not just your smile. Fox News. Fox News. 2012. Available at: http://www.foxnews.com/health/2012/03/28/dentalhygiene-important-for-whole-body-not-just-yoursmile. Accessed on 26 February 2016.

6. Moses J, Rangeeth B, Gurunathan D. Prevalence of dental caries, socio-economic status and treatment needs among 5 to 15 year old school going children of Chidambaram. J Clin Diagn Res. 2011;5:146-51. 
7. Rai B, Jain R, Kharb S, Anand S. Dental caries and oral hygiene status of 8 to 12 year school children of Rohtak: a brief report. Int J Dent Sci. 2006;5(1).

8. Soren AB, Mundle M, Das D, Chattachapadhyay S. A study of dental hygiene and decayed, missed, and filled status among patients attending dental OPD of Bankura Sammilani Medical College, India. The Health 2011.

9. Oral health surveys: basic methods $-5^{\text {th }}$ edition Geneva: WHO; 2013.

10. Ravishankar PL, Jayapalan CS, Gondhalekar RV, Krishna BJ, Shaloob KM, Ummer PF. Prevalence of dental caries and oral hygiene status among school going children: an epidemiological study. J Contemp Dent Pract. 2013;14(4):743-6.

11. Shingare P, Jogani V, Sevekar S, Patil S, Jha M. Dental caries prevalence among 3- to 14-year-old school children, Uran, Raigad District, Maharashtra. J Contemp Dentistr. 2012;2(2):11-4.

12. Karunakaran R, Somasundaram S, Gawthaman M, Vinodh S, Manikandan S, Gokulnathan S.
Prevalence of dental caries among school-going children in Namakkal district: a cross-sectional study. Journal of pharmacy \& bioallied sciences. 2014;6(1):S160-1.

13. Datta P, Datta PP. Prevalence of dental caries among school children in Sundarban, India. Epidemiol. 2013;3:135.

14. de Souza AL, Leal SC, Bronkhorst EM, Frencken JE. Assessing caries status according to the CAST instrument and WHO criterion in epidemiological studies. BMC Oral Health. 2014;14:119.

15. Venugopal T, Kulkarni VS, Nerurker RA, Damle SG, Patnekar PN. Epidemiological study of dental caries. Indian J Pediatr. 2000;65(6):883-9.

Cite this article as: Jain A, Jain V, Suri SM, Jain RK. Prevalence of dental caries in male children from 3 to 14 years of age of Bundelkhand region, India. Int $\mathbf{J}$ Community Med Public Health 2016;3:787-90. 